\title{
Lead-free Soldering: Materials Science and Solder Joint Reliability
}

\section{Kejun Zeng}

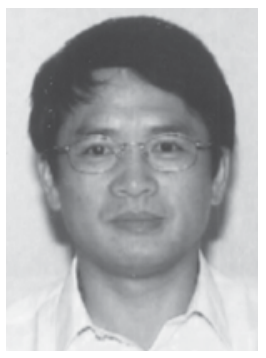

Since the National Electronics Manufacturing Initiative recommended Sn$3.9 \mathrm{Ag}-0.6 \mathrm{Cu}$ for reflow soldering and $\mathrm{Sn}-3.5 \mathrm{Ag}$ and $\mathrm{Sn}-0.7 \mathrm{Cu}$ for wave soldering in 2000, ${ }^{1}$ great effort has been made to address the reliability issues of lead-free soldered packages. Investigation of the dependence of properties of bulk solder alloys on compositions and processes can, of course, greatly help reliability engineering of solder joints. However, because of the strong effect of the interface between solder and soldered metal on the reliability of fine pitch solder joints, research of bulk solders is not enough to answer all the questions. The influences of composition and microstructure of solder joints on the reliability of bond interface should also be studied. In this issue, five papers address materials issues directly related to solder joint reliability.

In the first paper, I. Dutta et al. summarize their research in characterization of microstructural coarsening in Sn-Ag based solders and its effects on mechanical properties of bulk solder as well as reliability of solder joints. In the eutectic $\mathrm{SnAgCu}$ alloy, the volume fraction of $\mathrm{Cu}_{6} \mathrm{Sn}_{5}$ is much smaller than that of $\mathrm{Ag}_{3} \mathrm{Sn}$ and $\mathrm{Cu}_{6} \mathrm{Sn}_{5}$ coarsens more rapidly than $\mathrm{Ag}_{3} \mathrm{Sn}$. Therefore, $\mathrm{Ag}_{3} \mathrm{Sn}$ is the major contributor to the effects of coarsening on mechanical properties of $\mathrm{SnAgCu}$ solders and reliability of joints. The data indicate that a lower rate of interfacial failure of solder joints can be expected if electronic devices are handled with greater caution in the first several days after assembly.

The second paper by F. Guo et al. is an overview of their research results of $\mathrm{SnAgCu}$ solder with rare earth (RE) additions. RE elements can refine the microstructure of alloys. Because of this, resistance of $\mathrm{Pb}$-free solders to creep and thermal fatigue is improved. However, the resistance of SnAgCu-RE solders to surface oxidation remains a concern due to the susceptibility of RE elements to oxidation. Another potential issue is the growth of tin whiskers. Nevertheless, the authors believe that $\mathrm{SnAgCu}-\mathrm{RE}$ solders are now ready for reliability studies in electronic packages under severe service conditions.

In their paper, K. Nogita et al. reported experimental data that may have shed some light on why $\mathrm{SnAgCu}$ solder joints have a higher rate of interfacial failure than $\mathrm{SnPb}$ joints. Cracking of interfacial $\mathrm{Cu}_{6} \mathrm{Sn}_{5}$ crystals has been observed in the literature. Nogita et al. found that, prepared by the same procedure of cross sectioning, joints of $\mathrm{Ni}$ bearing solder systematically showed many fewer cracks in the interfacial intermetallic compound layer. The study concluded that $\mathrm{Ni}$ in the solder stabilized the hexagonal $\mathrm{Cu}_{6} \mathrm{Sn}_{5}$ to room temperature so that the stress buildup by phase transformation was avoided.

The fourth paper by Y.Y. Lee et al. studied the effects of alloying elements on the surface oxidation behavior of $\mathrm{Sn}$. It was found that $\mathrm{Cu}$ additions accelerated the oxidation of $\mathrm{Sn}$, but $\mathrm{Ag}$, $\mathrm{Ni}$, and In did the opposite. The reason for this difference was found in the microstructure of the oxide film. The surface oxide of $\mathrm{SnCu}$ alloy was more porous than those of the other alloys. The effects of these elements on the density of tin oxide are discussed in details.

V. Chidambaram et al. studied the effects of alloying elements on the corrosion resistance of the $\mathrm{Au}-\mathrm{Ge}-$ and $\mathrm{Au}-$
Sn-based high-temperature solders in the $\mathrm{NaCl}$ solutions. The Au-Sn-based candidate alloys near the eutectic point had higher corrosion resistance than the Au-Ge-based ones. That was because $\mathrm{Sn}$ helped to significantly reduce both the anodic and cathodic reactivities of Au-Sn-based alloys, but Ge was unable to do so. The authors point out that, even for Au-Sn-based solders, more investigations are necessary before they can replace high $\mathrm{Pb}$ solders in multi-chip modules whose applications involve high potential bias and high current density.

As mentioned earlier, the semiconductor industry faces many technical challenges in $\mathrm{Pb}$-free soldering where materials scientists might hold the solutions. For example, intermetallic compound formation at the solder/pad interface is not the only influential factor for solder joint reliability. Resistances of solders to thermal fatigue, ${ }^{2}$ recrystallization, ${ }^{3}$ and deformation at high strain rate $^{4}$ are even more critical. The industry is hoping that materials scientists would do more to address reliability issues of solder joints. Only with better understanding of the materials science behind various reliability issues can the packaging engineers fix the problems in a more cost-effective manner.

\section{References}

1. T. Costlow, EE Times (24 January 2000). 2. J.G. Lee and K.N. Subramanian, Microelectr. Reliab., 47 (2007), pp. 118-131.

3. T.T. Mattila and J.K. Kivilahti, J. Electr. Mater., 35 (2006), pp. 250-256.

4. F. Song et al., Proc. 9th Electr. Packag. Technol. Conf. (Piscataway, NJ: IEEE, 2007), pp. 463-470.

Kejun Zeng is a senior packaging engineer with Texas Instruments in Dallas, Texas and is the advisor to JOM from the Electronic Packaging and Interconnection Materials Committee of the Electronic, Magnetic, \& Photonic Materials Division of TMS. 